\title{
A physiological model of patient-reported breathlessness during daily activities
} in COPD

\author{
C.J. Jolley and J. Moxham
}

ABSTRACT: Breathlessness during daily activities has a significant impact on quality of life in chronic obstructive pulmonary disease. Herein, we present a physiological model of patientreported breathlessness based on the relationship between ventilatory load, respiratory muscle capacity, neural respiratory drive and neuromechanical dissociation during daily activities. This model should facilitate an understanding of the mechanisms driving increased intensity of breathlessness during daily activities and the relief of breathlessness following medical or surgical interventions.

The model should also provide a structure on which to base the development of patientreported outcome instruments to measure the severity of breathlessness during daily activities in chronic obstructive pulmonary disease.

KEYWORDS: Activities, chronic obstructive pulmonary disease, daily living, dyspnoea, pathophysiology, respiratory mechanics

$\mathbf{T}$ he Global Initiative for Chronic Obstructive Lung Disease (GOLD) defines chronic obstructive pulmonary disease (COPD) as a disease state characterised by exposure to a noxious agent resulting in airflow limitation that is not fully reversible [1]. This definition covers a spectrum of respiratory diseases, and includes both the clinical diagnosis of chronic bronchitis and the pathological diagnosis of emphysema. The worldwide prevalence of GOLD stage II or higher COPD has recently been estimated to be $10.1 \%$ [2]. COPD was the fourth most common cause of death worldwide in 2004, and was responsible for $5.1 \%$ of deaths. It is predicted to become the third leading cause of death by 2030 in association with projected increases in tobacco use, especially in low- and middle-income countries [3]. In 2004, 27,478 males and females living in the UK died of COPD, with $>90 \%$ of these deaths occurring in those aged $>65$ yrs [4].

COPD is characterised by symptoms of breathlessness, wheeze, cough, sputum production and exercise intolerance. Progression of COPD is almost invariably associated with increasing breathlessness, which has a negative impact on health-related quality of life. Breathlessness is a particularly dominant symptom in the final year of life, limiting patients' mobility both inside and outside of the home, and is associated with panic, anxiety and depression [5]. Patients with COPD are less active than sedentary, healthy elderly subjects and walk with lower movement intensity [6]. The impact of COPD on activity is not limited to patients with end-stage disease $[6,7]$.

The quality of life of patients with COPD should, therefore, be improved if breathlessness during daily activities can be reduced, with activities being increased and even resumed. In order to improve health-related quality of life, it is important to understand the pathophysiology of breathlessness during daily activities in COPD, as well as the physiological mechanisms of relief of breathlessness. It is also important to understand the links between the physiology of breathlessness and patients' reports of breathlessness when designing instruments to measure changes in breathlessness intensity, particularly when seeking to separate the proximal factors influencing breathlessness intensity from the impacts of breathlessness, which are distal outcomes [8]. Therefore, to facilitate this understanding, we aim to construct a physiological model of breathlessness during daily activities in COPD from the

\section{AFFILIATIONS}

King's College London School of Medicine, King's College Hospital London, UK.

\section{CORRESPONDENCE}

C.J. Jolley

Dept of Asthma

Allergy \& Respiratory Science

King's College London School of Medicine

King's College Hospital

Bessemer Road

London SE5 9PJ

UK

E-mail: caroline.jolley@kcl.ac.uk

Received:

December 172008

Accepted after revision:

March 022009

\section{STATEMENT OF INTEREST}

C.J. Jolley and J. Moxham have a consultancy agreement with GlaxoSmithKline. The development of the physiological model and the manuscript was supported by an unrestricted grant from

GlaxoSmithKline.

\section{PROVENANCE}

Publication of this peer-reviewed article was made possible by funding from GlaxoSmithKline, UK (principal sponsor, European Respiratory Review issue 112). 
patient's perspective. Although several authors have considered the physiological mechanisms of breathlessness in COPD [9-11], few have sought to compile these into a physiological model of breathlessness that explains patients' descriptions of breathlessness during daily activities in COPD beyond the impact of disordered ventilatory mechanics on exertional breathlessness in general.

\section{DEFINITION OF BREATHLESSNESS}

A consensus definition of breathlessness is that of "a subjective experience of breathing discomfort that consists of qualitatively distinct sensations that vary in intensity" [12]. As will be discussed later, the sensation of breathlessness is ultimately a result of the activation of proprioceptive pathways during the act of breathing. Until the latter half of the 20th century, studies focused on the role of pulmonary mechanics, the work of breathing, vagal and chest wall afferents, and blood gas abnormalities on breathlessness [13]. It is also important to recognise the importance of the interaction between neurophysiology and psychology when considering breathlessness from the patient's perspective. Breathlessness is experienced and interpreted by the individual. Therefore, qualitative studies of patients' descriptions of breathlessness are complementary to quantitative physiological studies when considering the origins of breathlessness from the patient's perspective.

\section{PHYSIOLOGY OF BREATHLESSNESS}

The sensation of breathlessness is closely related to the sensation of respiratory effort, suggesting common neurophysiological origins [14]. Analogies have been drawn with the sense of effort during limb movement, which is related to activation of proprioceptive afferents and a conscious awareness of efferent motor command [15]. In simple terms, the sensation of respiratory effort, and therefore of breathlessness, is increased when the load on the respiratory muscles increases, the capacity of the respiratory muscles decreases or there is a combination of both factors [15]. When there is load-capacity imbalance, neural drive to the respiratory muscles (neural respiratory drive; NRD) from the medullary respiratory centre increases to maintain gas exchange and respiratory homeostasis. Conscious awareness of the level of NRD is important to the perception of breathlessness, regardless of the nature of the stimulus (chemical or mechanical) activating sensory neural afferents (fig. 1) [16]. In the 1963, CAMPBell and Howell [17] proposed the theory of "lengthtension inappropriateness" or "efferent-afferent mismatch", which explains breathlessness in these terms. The central tenet of this hypothesis is that the brain "expects" a certain pattern of ventilation and feedback for a given level of NRD. Deviation of the afferent signal from that predicted causes or intensifies the sensation of breathlessness. The sensory afferents involved include pulmonary stretch receptors and intercostal muscle spindles (stimulation of these reduces breathlessness [18, 19]). Stimulation of peripheral and central chemoreceptors by hypercapnia [20] and/or hypoxia, irritant receptors [21] and possibly C fibres [22] increases breathlessness. There is physiological evidence to support this hypothesis; for example, constraining respiratory rate and tidal volume when NRD is increased during carbon dioxide rebreathing increases breathlessness [23]. Vibration over parasternal intercostal muscles in phase with inspiration, which stimulates muscle spindles and increases appropriate afferent feedback, reduces breathlessness in patients with chronic lung disease, but vibration over the parasternal region during expiration increases breathlessness [24]. In phase vibration has been also shown to reduce ventilatory drive in COPD and could, therefore, reduce breathlessness by having an impact on both sides of the efferentafferent balance [25].

Higher brain centres are important to both respiratory control and to the perception of breathlessness. Respiration can also be under voluntary control [26], so that automatic breathing can be interrupted by speech, coughing, eating, etc. Physiological studies, together with functional brain imaging, are beginning to elucidate the brain areas involved in the neural processing of breathlessness [9]. Consistent with the importance of emotion on the sensation of breathlessness, these include cortical and subcortical areas involved in the sensorimotor control of breathing and limbic regions [27]. These studies suggest that there are common neural pathways for the processing of breathlessness and pain. For example, functional imaging suggests the involvement of the anterior insular cortex in the sensation of both pain and air hunger [28]. This reflects psychophysiological similarities between experiences of breathlessness and pain. Both are distressing, multidimensional sensations with a significant emotional component that require a variety of mechanisms for the arousal, detection and triggering of appropriate motor responses to correct actual or threatened disturbances to homeostasis [29].

The following sections will build on the "generic" model of breathlessness described above to consider the importance of increased load, reduced ventilatory capacity and efferentafferent mismatch to the sensation of breathlessness in COPD,

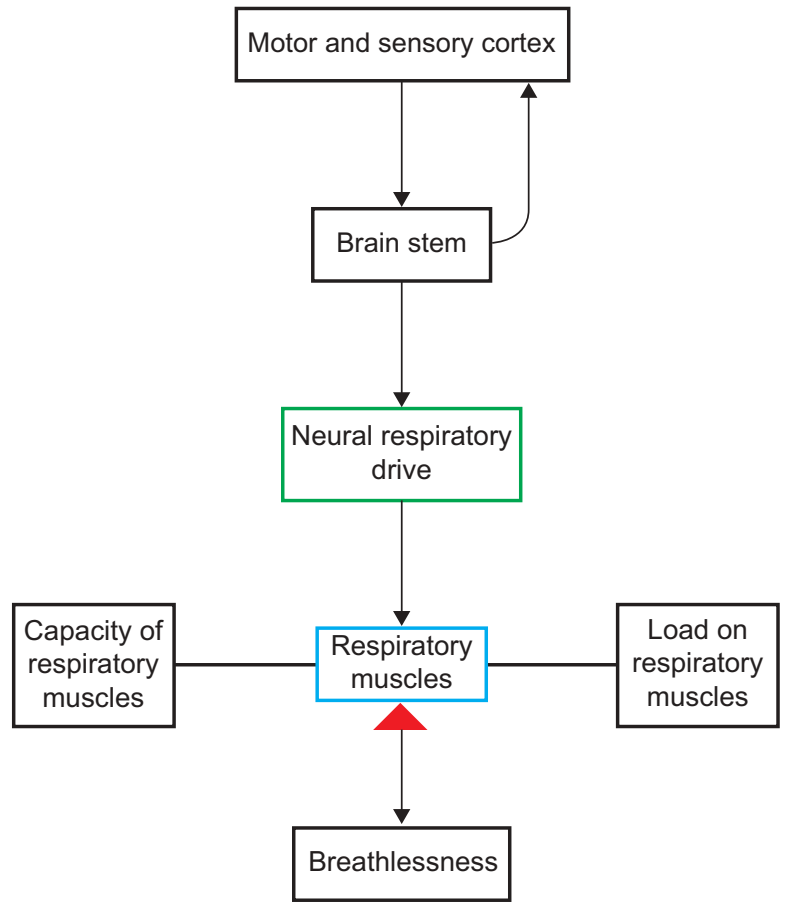

FIGURE 1. Increased load and/or reduced capacity of the respiratory muscles leads to an increased level of neural respiratory drive to the respiratory muscles. Conscious awareness of the level of neural respiratory drive is important to the perception of breathlessness [16] 
how these relationships change during different activities of daily living, and how the physiological processes involved may influence patients' choice of descriptors of breathlessness. Since the pathological processes are proximal to the physiological ones, they are best considered first.

\section{PATHOLOGY OF COPD}

The pathology of COPD has been extensively reviewed elsewhere [30,31] and is briefly discussed here to highlight mechanisms underlying the disordered physiology relevant to the physiological model. The link between pathological changes, characteristics of COPD, symptoms and quality of life is also summarised in figure 2.

\section{Triggers}

It is widely accepted that cigarette smoking is the most important risk factor for COPD [32]. Air pollution, airway infections and occupational exposures, for example to coal dust and silica dust, are also implicated [33]. $\alpha_{1}$-Antitrypsin deficiency is the only conclusively proven genetic factor predisposing individuals to the development of emphysema [34]. Further details on the genetics of COPD have been published elsewhere [35-37].

\section{Inflammatory mechanisms in COPD}

Inflammatory processes within the lung

Cigarette smoke and other environmental stimuli trigger chronic inflammation, involving an inflammatory cell infiltrate (including alveolar macrophages, neutrophils and cytotoxic Tlymphocytes), the release of multiple inflammatory mediators [37] and increased levels of oxidative stress [38]. The inflammatory response induces goblet-cell metaplasia [39], mucus hypersecretion [40], airway smooth muscle hypertrophy [41] and mucociliary dysfunction [42]. Lung parenchymal connective tissue is broken down by proteinases released by activated inflammatory cells, including serine proteinases, neutrophil elastase, proteinase $C$, cathepsins and matrix metalloproteinases [43]. Proteinases also stimulate mucus hypersecretion [44]. Mucus hypersecretion and mucociliary dysfunction are favourable conditions for colonisation with, and infection by, viruses and bacteria, and infective exacerbations of COPD are a cause of acute-on-chronic airway and systemic inflammation $[45,46]$. Frequent exacerbations are associated with an accelerated decline in lung function over time [47].

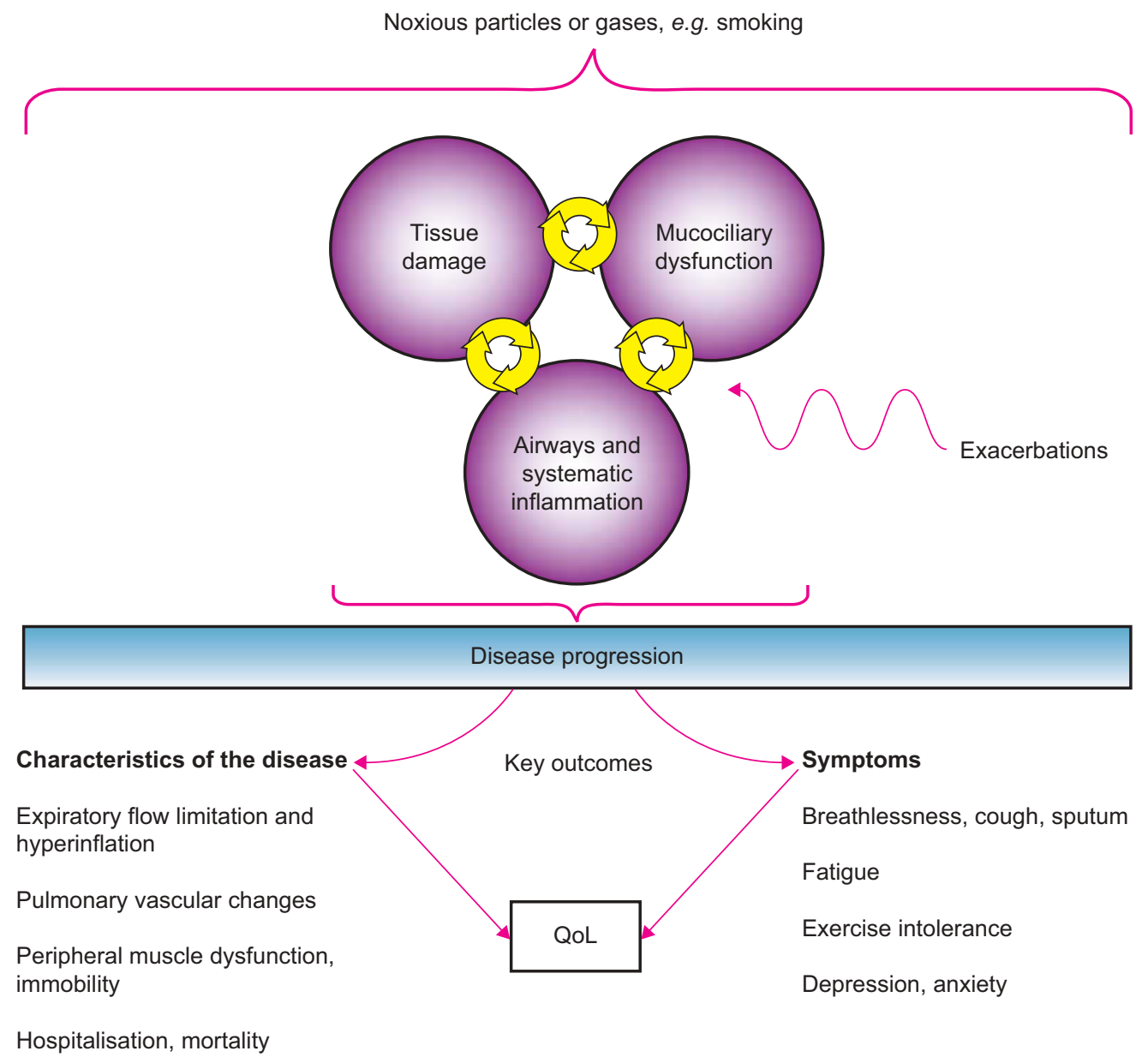

FIGURE 2. The relationship between triggers, pathological changes, disease characteristics, symptoms and quality of life (QoL) in chronic obstructive pulmonary disease (COPD). Inhaled environmental noxious stimuli, particularly cigarette smoke, trigger a cycle of pulmonary parenchymal and airway damage, mucociliary dysfunction and airway and systemic inflammation. This cycle is also driven by exacerbations. Breathlessness is one of the cardinal symptoms of COPD and has a negative impact on QoL, in particular by reducing patients' exercise tolerance and ability to carry out daily activities. 


\section{Systemic inflammation}

Inflammation in COPD is not restricted to the lungs, and systemic inflammation is also associated with clinically significant changes in biochemistry and organ function [4850], including cachexia, weight loss, osteoporosis, muscle wasting, heart failure, atherosclerosis, dementia, depression and cancer [48, 51, 52]. The level of systemic inflammation has been shown to be related to the depletion of fat-free mass [53, 54], and is thought to contribute to the development of quadriceps muscle dysfunction in COPD [48]. However, cause and effect is still to be definitively established for the link between inflammation/oxidative stress and peripheral muscle dysfunction, and deconditioning due to immobility is also likely to contribute substantially [55].

\section{Peripheral muscle changes in COPD}

A landmark study by KILLIAN et al. [56] established that the exercise tolerance of patients with COPD is often limited by leg discomfort as well as by breathlessness. Subsequently it was shown that the quadriceps of patients with COPD are weaker than those of aged-matched control subjects [57]. The finding that the mean cross sectional area of IIA/IIX and IIX fibre types is reduced in the quadriceps of COPD patients is consistent with this observation [58]. Lower limb weakness is associated with exercise intolerance, and the severity of breathlessness during exercise, in COPD [59, 60]. Lower limb muscle endurance is also impaired in COPD [61, 62], and early contractile fatigue of the leg muscles has also been shown to limit exercise capacity [63]. Quadriceps biopsies in COPD have shown a loss of aerobic type I fibres [64] and reduced oxidative enzymes [65]. Consistent with this, the aerobic capacity of the peripheral muscle is reduced, and early onset of lactic acidosis appears to be involved in early exercise termination in severe COPD patients during incremental exercise tests [66]. Ventilation must increase to eliminate the excess carbon dioxide produced when lactate is buffered by bicarbonate.
As discussed later, this increase in ventilatory drive is important to the development of breathlessness.

\section{Pulmonary vascular changes}

Pulmonary hypertension (PH) in COPD progresses slowly [67, 68] and its severity correlates with the degree of airflow obstruction and the impairment of pulmonary gas exchange [67]. PH may develop during exercise even if not present at rest [69]. Severe $\mathrm{PH}$ increases right ventricular afterload and eventually leads to the clinical syndrome of right-sided heart failure with systemic congestion and inability to adapt right ventricular output to cardiopulmonary demands during exercise. $\mathrm{PH}$ increases ventilation/perfusion mismatch, impairs gas exchange and has been shown to reduce exercise capacity in pulmonary fibrosis [70]. The extent to which $\mathrm{PH}$ limits exercise tolerance in COPD has not been fully investigated.

\section{PHYSIOLOGICAL IMPACT OF THESE PATHOLOGICAL CHANGES}

The principles discussed below are summarised in figure 3 . The mechanical load on the respiratory muscles is increased in COPD. The cardinal mechanical abnormality is that of expiratory airflow limitation. The major site of increased airway resistance in most individuals with COPD is the small airways, those with a diameter of $\leqslant 2 \mathrm{~mm}$ [71], although there are pathological changes within both the large and small airways. As described previously, airway narrowing occurs secondary to the inflammatory processes, mucus production and, in some individuals, airway smooth muscle hypertrophy. The loss of elastic recoil secondary to elastinolysis within the lung parenchyma results in loss of radial traction on the bronchioles. The reduced (inward) lung recoil pressure requires a greater volume to balance the (outward) chest wall recoil, and, therefore, functional residual capacity (FRC) increases ("static hyperinflation"). The mechanical time constant for lung emptying, given by the product of resistance and

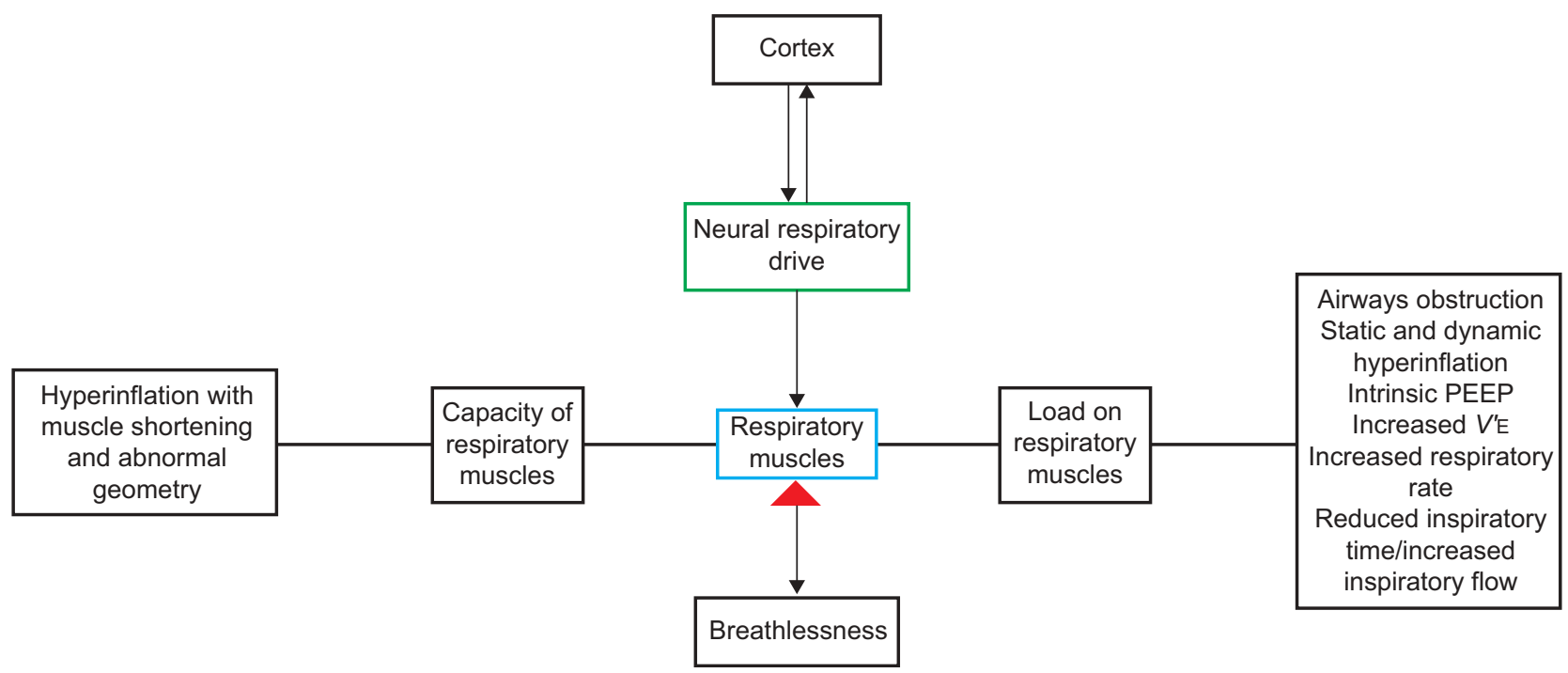

FIGURE 3. The impact of disordered ventilatory mechanics on breathlessness in chronic obstructive pulmonary disease (COPD). Static and dynamic hyperinflation leads to respiratory muscle shortening and altered chest wall geometry, leading to functional respiratory muscle weakness in COPD. This, in combination with mechanical abnormalities that increase the load on the respiratory muscles, increases load-capacity imbalance and neural respiratory drive, and contributes to breathlessness. Although these abnormalities may be present at rest, they are exacerbated when minute ventilation $\left(V^{\prime} E\right)$ increases during activity. PEEP: positive end-expiratory pressure. 
compliance, is also increased in COPD. The maximum rate of lung emptying is decreased and air is trapped in the alveoli at the end of expiration, which results in "dynamic hyperinflation" during exercise when the respiratory rate increases and expiratory time shortens [72]. Dynamic hyperinflation (DH) is initially favourable as increased radial traction on the airways holds the airways open, thereby reducing resistance to expiratory flow. However, as $\mathrm{DH}$ progresses, there are negative consequences for lung mechanics. If hyperinflation is severe, end-expiratory lung volume (EELV) moves above the relaxation volume of the chest wall, and so at EELV the chest wall will recoil inwards. This represents an increase in the inspiratory elastic load in addition to lung elastic recoil, and therefore adds to the work of breathing. Increased intrinsic positive end-expiratory pressure, developing as a consequence of gas trapping, also imposes an additional inspiratory threshold load that must be overcome before intrathoracic pressure falls below atmospheric pressure and inspiratory airflow can begin [73]. As FRC increases towards total lung capacity (TLC) during exercise in COPD, this encroaches on inspiratory reserve volume and inspiratory capacity decreases until it is impossible to increase tidal volume, and minute ventilation $\left(V^{\prime} \mathrm{E}\right)$ can only be increased by increased respiratory rate [74]. The ratio of inspiratory time to the duration of the respiratory cycle is reduced in an effort to increase the time available for expiration and minimise hyperinflation, which demands an increase in the inspiratory flow rate. In COPD, the dynamic elastance of the lung and chest wall is linearly related to inspiratory flow rate [75]; therefore, this imposes an additional inspiratory load on the inspiratory muscles during exercise.

COPD patients must also generate an increased $V^{\prime} \mathrm{E}$ to maintain respiratory homeostasis when compared with healthy subjects. The pathological changes described previously increase physiological dead space and, therefore, there is significant ventilation/perfusion mismatch in COPD [76]. During exercise, the reduced aerobic capacity of the peripheral muscles, coupled with cardiopulmonary constraints on oxygen delivery exacerbated by coexistent cardiovascular disease in many patients, leads to lactic acid production at relatively low work rates, which increases ventilatory drive further despite the mechanical constraints to increased ventilation described previously.

\section{The capacity of the respiratory muscles is reduced in COPD}

The capacity of the inspiratory muscles to generate negative intrathoracic pressure is reduced in COPD [77]. Hyperinflation alters the geometry of the respiratory muscles such that the diaphragm sarcomeres are shortened. Since the tension a muscle generates is related to its length [78], hyperinflation reduces the force-generating capacity of the diaphragm. In addition, as the diaphragm flattens, the radius of curvature of the diaphragm is increased and the flattened diaphragm is therefore less effective at converting tension into pressure in accordance with Laplace's law. Hyperinflation also reduces the zone of apposition of the diaphragm [79], which reduces the ability of the diaphragm to expand the lower rib cage during inspiration [80]. POLKEY et al. [81] demonstrated a linear negative correlation of twitch transdiaphragmatic pressure with increasing lung volume of $3.5 \mathrm{cmH}_{2} \mathrm{O} \cdot \mathrm{L}^{-1}$, an effect which was mediated by the reduction in twitch transoesophageal pressure. The ability of the diaphragm to generate transdiaphragmatic, and particularly intrapleural, pressure is therefore reduced in COPD and these changes are exaggerated with acute-on-chronic hyperinflation.

Therefore, the overall impact of hyperinflation is an increase in the inspiratory pressure needed to increase tidal volume as tidal volume approaches TLC, an increase in the inspiratory threshold load, and an increase in the level of effort required to increase the inspiratory pressure as the capacity of the respiratory muscles decreases. Thus $\mathrm{DH}$ increases the load on the respiratory muscles and reduces their capacity during exercise in COPD. Consistent with the generic physiological model of breathlessness described previously, by increasing load-capacity imbalance, $\mathrm{DH}$ increases the intensity of breathlessness during exercise in COPD [82]. Conversely, reduction of DH using long-acting bronchodilators [83] or nonpharmacological lung volume reduction [84] reduces respiratory muscle work and improves exertional breathlessness in COPD. DH is also reduced indirectly by interventions that reduce ventilatory drive and increase the proportion of the respiratory cycle available for expiration. Exercise training, particularly exercise targeting the quadriceps muscle, during pulmonary rehabilitation reduces the ventilatory response to exercise, DH and breathlessness [85]. Similarly, oxygen therapy reduces the intensity of breathlessness during exercise, even in non-hypoxaemic patients, by reducing $V^{\prime} \mathrm{E}$, increasing the duration of expiration and therefore reducing $\mathrm{DH}$ [86].

\section{Neural respiratory drive is increased in COPD}

In response to increased load (including the metabolic demands of quadriceps muscle dysfunction) and reduced capacity, levels of NRD are increased in COPD. This has been demonstrated by findings of increased transdiaphragmatic pressure generation [87], and increased firing rates in the motor units of the diaphragm [88] and extradiaphragmatic inspiratory muscles in COPD [89]. Levels of NRD can be measured by recording the diaphragm electromyogram (EMGdi) using oesophageal recording electrodes, quantifying NRD as EMGdi per breath as a percentage of maximum EMGdi during forced inspiratory manoeuvres. Studies using this method have shown that NRD is significantly higher in COPD patients compared with matched healthy controls [90, 91], and that levels of NRD are correlated with disease severity defined by spirometry and the degree of hyperinflation [91]. As described previously, conscious awareness of the level of NRD is important to the perception of breathlessness [16]. Consistent with this, cold air reduces breathlessness in COPD by inducing a relative hypoventilation during exercise [92], although reductions in efferent-afferent mismatch through stimulation of upper airway cold receptors [93] could also be important. Opioids reduce ventilatory drive [94-96], but observations that opioid-induced reductions in breathlessness occur without evidence of hypoventilation indicates that other mechanisms, such as reduction of anxiety and emotional distress, are likely to be more important to the palliation of breathlessness by these drugs $[97,98]$. Inhaled opioids and furosemide may also palliate breathlessness by sensitising pulmonary stretch receptors, thus increasing afferent feedback [99]. 


\section{Neuromechanical dissociation increases efferent-afferent mismatch during exercise in COPD}

SINDERBY et al. [100] measured diaphragmatic pressure and EMGdi during exhaustive exercise in COPD, showing that DH reduces diaphragm pressure-generating capacity and promotes high levels of diaphragm activation. Whereas transdiaphragmatic pressure and $V^{\prime}$ E plateaued at a relatively low level shortly after the onset of exercise, EMGdi continued to rise to $\sim 80 \%$ of maximum [100]. This study demonstrates that because of the mechanical constraints described above, NRD becomes progressively uncoupled from mechanical and ventilatory output in $\mathrm{COPD}$, i.e. there is neuromechanical dissociation (fig. 4). Neuromechanical dissociation will increase the efferent-afferent mismatching that drives breathlessness. The intensity of perceived inspiratory difficulty during exercise has been shown to correlate well with increases in the effort/displacement ratio, a crude index of neuromechanical dissociation, which is defined as the ratio between tidal swings of oesophageal pressure expressed as a proportion of maximum inspiratory pressure and the tidal volume response expressed as a proportion of predicted vital capacity [10]. It has been proposed that once the inspiratory reserve volume has fallen to a critical level, the effort/ displacement ratio rises sharply, reflecting unfavourable ventilatory mechanics and inspiratory muscle weakness as DH progresses, driving increases in breathlessness to intolerable levels [101]. Improvements in exertional breathlessness following treatment with the long-acting bronchodilator tiotropium bromide have been shown to be associated with improvements in the effort/displacement ratio [101].

It has been suggested that temporary suppression of breathing during speaking or eating increases mismatch between the respiratory motor command and afferent feedback from peripheral receptors, especially when levels of NRD are already high, such as in COPD [102]. However, it should be noted that, in general, COPD patients experience breathlessness most during exertion rather than whilst eating or talking [103].

\section{Breathlessness during daily activities in COPD can be explained in terms of common physiological mechanisms}

The pathological processes, physiological changes, perception of breathlessness and impact on exercise tolerance and quality of life in COPD can be linked together in a conceptual model that can be used to explain the physiological mechanisms by which daily activities lead to the perception of breathlessness in COPD. This model is shown in figure 5. The key common physiological factors in COPD are increased ventilatory load, reduced ventilatory capacity and increased NRD, hyperinflation and neuromechanical dissociation, leading to an efferentafferent mismatch which drives breathlessness (grouped together under "physiology" in the model). Different daily activities may feed into different levels of this physiological "hierarchy", but the physiological mechanisms are ultimately similar. As will be expanded upon later, breathlessness then increases in intensity and unpleasantness ("perception"). This reduces exercise tolerance and impairs quality of life ("impact").

\section{Lower limb activities, e.g. walking, climbing stairs}

As described previously, there is a well established link between peripheral muscle dysfunction, reduced aerobic capacity, increased cardiopulmonary demand and ventilatory drive that contributes to breathlessness during daily activities using the lower limbs in terms of the conceptual model. As described in previous sections, lactic acid accumulation early in exercise, due to the reduced aerobic capacity of lower limb muscle, necessitates further increases in ventilation relatively early in exercise to buffer excess carbon dioxide. Increased $V^{\prime} \mathrm{E}$ and DH increase respiratory muscle load-capacity imbalance, which increases NRD and ultimately increases efferentafferent mismatch which, in turn, drives breathlessness.

\section{Upper limb activity}

Breathlessness during daily activities that require upper limb activity, e.g. grooming and dressing, impact on quality of life to at least the same extent as ambulatory activities limited by quadriceps muscle dysfunction [104]. This is not due simply to

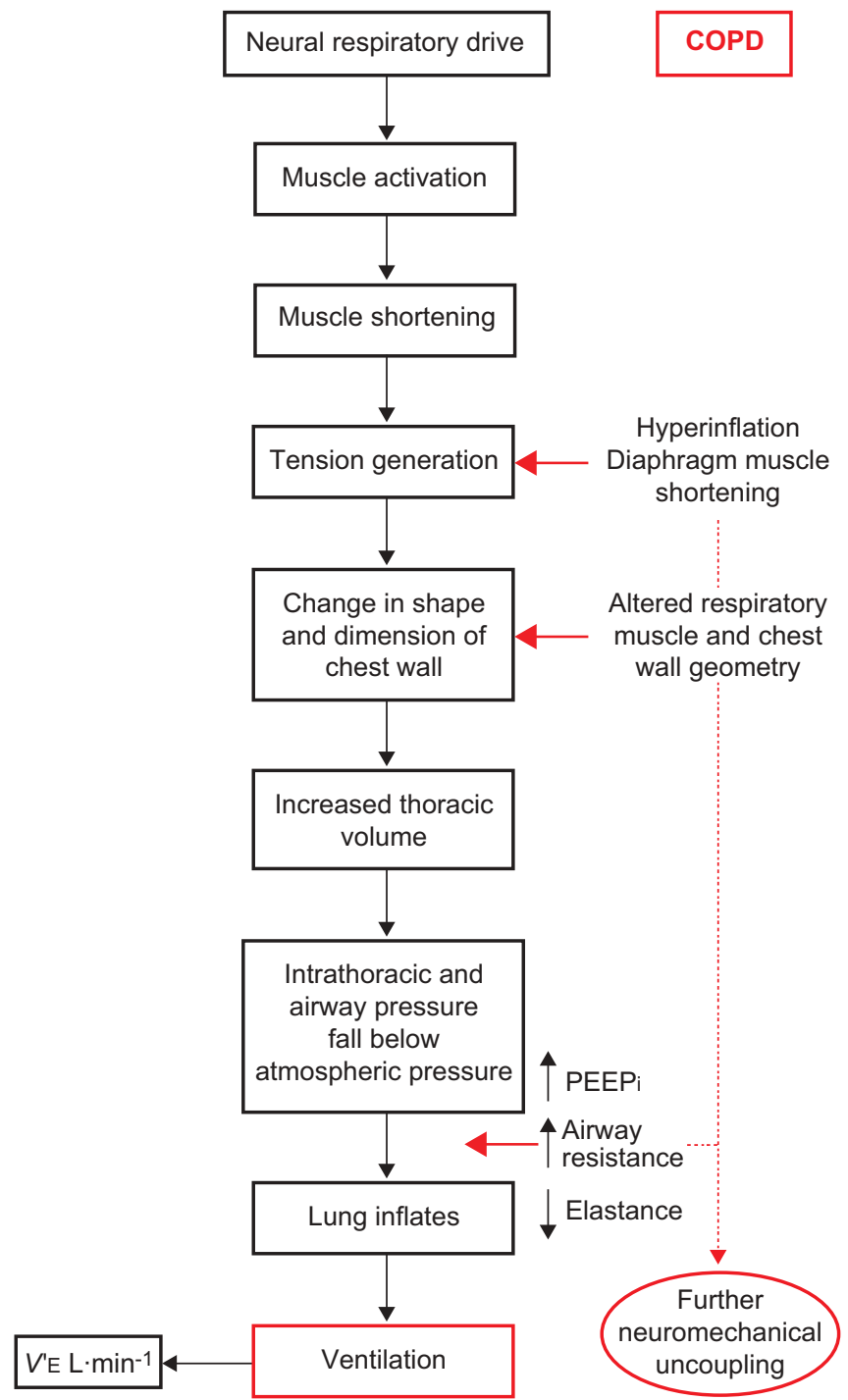

FIGURE 4. Disordered ventilatory mechanics progressively uncouple increased neural respiratory drive from generation of respiratory muscle tension, intrathoracic pressure and ventilation in chronic obstructive pulmonary disease (COPD). This phenomenon is often referred to as "neuromechanical dissociation". PEEPi: intrinsic positive end-expiratory pressure; $V^{\prime} E$ : minute ventilation. 
the metabolic and cardiorespiratory demands of upper limb muscle contraction. Indeed, the mechanical efficiency and exercise capacity of the upper and lower limbs are not homogeneously affected in COPD, with a relative preservation of the upper limb muscle function [105]. As described below, studies indicate that upper arm exercise has an additional adverse impact on ventilatory mechanics. It is also important to consider that many of the respiratory and upper limb muscles have at least dual roles. As well as being recruited during respiration, they may also be involved in generating the movement (especially those of the scapular girdle) and/or acting as postural muscles to stabilise the torso and chest during upper limb movement. This reduces the ventilatory reserve of these muscles during upper limb exercise, thus increasing the load on the diaphragm and other respiratory muscles.

Any activity that involves the use of the arms increases the load on the respiratory system because ventilation must

4. Impact

3. Perception

Intensity
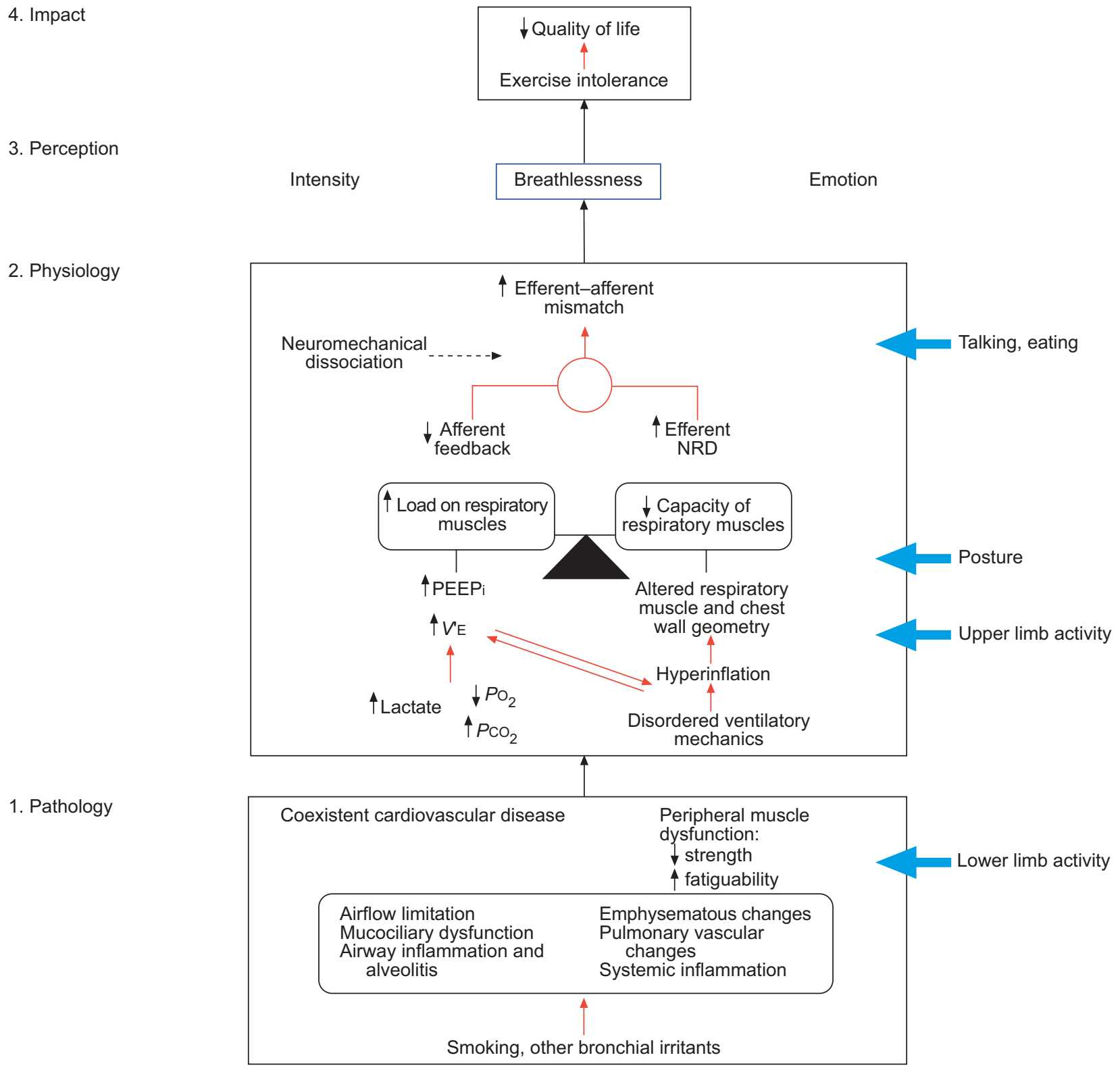

FIGURE 5. A physiological model of breathlessness in chronic obstructive pulmonary disease. The model links the pathological processes triggered by inhaled noxious particles (1) to physiological factors leading to respiratory muscle load-capacity imbalance and efferent-afferent mismatch (2). This drives the perception of breathlessness (3) and results in exercise intolerance and reduced quality of life (4). In line with patients' descriptions of their experience of breathlessness, there is evidence that intensity (sensory) and emotional (affective) components of breathlessness are processed separately in the brain. Lower limb activity, upper limb activity and postural changes required to carry out daily activities increase load-capacity imbalance, neural respiratory drive, efferent-afferent mismatch and breathlessness. Activities that interrupt the automatic rhythm of respiration, e.g. eating and talking, reduce ventilation transiently and may cause breathlessness through resultant increases in efferent-afferent mismatch. NRD: neural respiratory drive; PEEPi: intrinsic positive end-expiratory pressure; $V^{\prime} E$ : minute ventilation; $\mathrm{PO}_{2}$ : oxygen tension; $P \mathrm{CO}_{2}$ : carbon dioxide tension. 
increase to meet the metabolic demands of limb muscle contraction. As described earlier, an increase in respiratory rate coupled with a reduction in expiratory time leads to $\mathrm{DH}$ in COPD, with deleterious effects on ventilatory mechanics, neuromechanical dissociation and efferent-afferent mismatch. $\mathrm{DH}$ has been shown to occur with arm exercise in cystic fibrosis patients with expiratory flow limitation, to an extent that is not significantly different from that observed during leg exercise [106]. Conversely, an arm training protocol increased arm endurance, reduced $\mathrm{DH}$ and reduced exertional breathlessness in COPD [107].

COUSER JR et al. [108] showed that the simple elevation of the arms of normal individuals results in a significant increase in oxygen uptake $\left(V^{\prime} \mathrm{O}_{2} ; 16 \%\right)$ and in ventilation $(24 \%)$, and an increase in the end-inspiratory gastric $(P$ ga $)$ and transdiaphragmatic pressure $(P \mathrm{di})$. Although the metabolic and ventilatory demand remained increased for a short time when the arms returned to their sides, Pga dropped suddenly. This suggests that arm elevation changes the mechanics of the chest and abdominal compartments during respiration, and that these increased demands are associated with an increased diaphragmatic contribution to the generation of ventilatory pressures. Similarly, CELLI et al. [109] studied the impact of upper arm exercise on respiratory muscle activity (measuring oesophageal pressure, $P$ ga and $P$ di) in healthy subjects. Upper arm exercise resulted in a shift of the dynamic work to the diaphragm, and to the abdominal muscles, i.e. away from the ribcage muscles that would be used as postural muscles during the exercise. If the diaphragm is already heavily loaded and at a functional disadvantage in COPD, one could hypothesise that upper arm exercise would increase neuromechanical dissociation further, and that COPD patients would become more breathless during arm exercise than healthy subjects.

In 1973, TANGRI and WOOLF [110] observed that patients with COPD acquired an irregular, shallow and rapid respiratory pattern when performing activities requiring the upper limbs, such as tying a pair of shoes and their combing hair. A later study by CELLI et al. [111] showed that unsupported arm exercise in patients with COPD led to thoracoabdominal dyssynchrony and dyspnoea within a shorter period of time and at a lower $V^{\prime} \mathrm{O}_{2}$ than leg exercise. Velloso et al. [112] studied COPD patients during four activities of daily living involving varying degrees and patterns of upper limb muscle recruitment. The sensation of breathlessness measured using the Borg scale was higher in the activities involving changing light bulbs and lifting pots (i.e. those requiring a greater contribution from the scapular musculature), although the metabolic demands and levels of ventilation were not necessarily increased relative to other activities. Although pulmonary mechanics and neural drive were not measured, this suggests that the symptom of breathlessness could be related to patterns and extent of respiratory muscle activation, rather than to metabolic or ventilatory demands per se.

In summary, during upper limb exercise there is increased $V^{\prime} \mathrm{E}$, $\mathrm{DH}$, increased mechanical load and reduced capacity of the respiratory muscles in the usual manner. However, in addition, ventilatory reserve is reduced further because the upper limb muscles are involved in generating the movement, acting as postural muscles and being recruited during respiration. The relative contribution of the diaphragm to ventilation increases. These factors increase neuromechanical dissociation, leading to efferent-afferent mismatch and breathlessness.

\section{Posture}

Some, but not all, patients feel that breathlessness is relieved or exacerbated when their posture changes e.g. sitting up from lying flat and vice versa, or breathlessness is induced or increased when bending over to tie shoelaces [104]. COPD patients who recruit their rib cage muscles during resting breathing experience postural relief of dyspnoea when adopting a position associated with reduction in rib cage muscle activation [113] or neck muscle activation, such as during the forward leaning position [114]. The effect of posture on respiratory muscle strength has been studied noninvasively in normal subjects and COPD patients recovering from an exacerbation. In healthy subjects there is no effect of posture on maximum static inspiratory or expiratory pressures. The seated leaning-forward position was the preferred posture in the majority of the COPD patients in the acute phase, and maximum static inspiratory pressure was greater in the seated leaning-forward position than in the other positions studied. Posture had no influence on maximum static expiratory pressure in the COPD patients [115].

The relationship between pulmonary mechanics, respiratory muscle function and breathlessness is complex. In the same way as when COPD patients are upright, breathlessness when lying down is thought to result, in part, from increased inspiratory efforts due to dynamic pulmonary hyperinflation and the concomitant increase in inspiratory threshold load due to intrinsic positive end-expiratory pressure. In addition, airway resistance is increased when supine compared to when upright due to a relative reduction in EELV, which reduces the patient's ability to adapt to expiratory flow limitation by breathing at a higher lung volume, thus increasing the load on the respiratory muscles further and inducing breathlessness [116]. However, the pressure-generating capacity of the diaphragm has been shown to be greater in the supine rather than in the erect position in severe, hyperinflated COPD patients (this is not seen in healthy subjects) [117]. Whether or not an individual patient has relief of breathlessness when changing from the upright to the lying position (or vice versa) appears to be related to resultant levels of neuromechanical dissociation. In patients who have postural relief of breathlessness, the relationship between Pdi and EMGdi measured using a combined oesophageal EMGdi/pressure catheter, expressed as the Pdi/EMGdi ratio (a measure of neuromechanical efficiency), has been observed to be higher when supine than erect, indicating that neuromechanical dissociation is higher in the erect than in the supine position, i.e. Pdi fell and EMGdi increased going from the supine to the erect position. Therefore, a given pressure could be achieved with lower levels of NRD when supine in these patients. Patients who did not have postural relief from breathlessness demonstrated less reduction in Pdi going from the supine to the erect position, and a reduction in EMGdi relative to that recorded in the supine position [118]. This indicates that the degree of neuromechanical dissociation is an important factor driving 
postural changes in the experience of breathlessness in COPD.

\section{The physiological mechanisms driving breathlessness may be reflected by descriptors of breathlessness}

A significant amount of work has been carried out on the relationship between qualitative aspects of breathlessness and physiological mechanisms [119-121]. There is little evidence to support the uniqueness of certain terms to specific conditions [122], but descriptors of breathlessness do appear to fall into "clusters", which may reflect activation of common neurophysiological processes to produce similar sensations of breathlessness, even in different diseases. The current literature supports the existence of four distinct somatic descriptions of breathlessness: 1) perceived sense of increased work or effort; 2) sense of chest tightness; 3 ) air hunger or an uncomfortable urge to breathe; and 4) unsatisfied inspiration [9]. Descriptors of increased work/effort are commonly used to describe breathlessness in COPD, and also in interstitial lung disease, neuromuscular disease and chest wall disease [123]. Similarly, in asthma, although "chest tightness" is used to describe breathlessness at low levels of bronchoconstriction and a relatively normal forced expiratory volume in on second, the sensation of work/effort increases when significant airways resistance or hyperinflation develops [124]. One common factor linking these conditions is increased load-capacity imbalance with respect to the respiratory muscles, giving rise to the sensation of increased respiratory effort. Other commonly used descriptors in COPD include air hunger, need to breathe and urge to breathe [123]. Air hunger is also experienced by healthy subjects when ventilation is stimulated by hypercapnia, even after total neuromuscular paralysis [20]. Air hunger can also be experienced independently of work/effort when neuromuscular transmission is intact [125]. Together such studies indicate that, unlike work/effort, air hunger is not due to awareness of the increase in ventilation or respiratory muscle contraction, but could be explained either by increased medullary chemoreceptor activity, awareness of increased efferent motor command, or an imbalance between the chemical drive to breathe and achieved ventilation (efferent-afferent mismatch). Subjects can differentiate between sensory (intensity) and affective (unpleasantness) components of breathlessness [126]. In COPD, the development of breathlessness-related anxiety during exercise has been shown to be different to that of the awareness that the intensity of breathlessness has increased [127]. There is some evidence that these sensations involve neural processing in separate cortical areas [128].

\section{DISCUSSION}

The physiological impact of daily activities causing breathlessness in COPD can be considered in terms of their impact on the load on the respiratory muscles, the capacity of the respiratory muscles and the neuromechanical dissociation that results. Efferent-afferent mismatch appears to be one of the most important, final common steps driving the sensation of breathlessness in COPD. There is evidence that, although interrelated, intensity (sensory) and emotional (affective) components of breathlessness are processed separately (fig. 5). The physiological mechanisms by which interventions impact on breathlessness by reducing neuromechanical dissociation and efferent-afferent mismatch can also be explained in terms of the physiological model (fig. 6). Psychological factors are considered to be distal to physiological factors in the model, and so they will not be considered further here. The impact of psychological interventions, such as counselling and support programmes and psychotherapy, on breathlessness are variable [129]. There is currently insufficient evidence to recommend the use of such interventions alone for the palliation of breathlessness in routine clinical practice [129], although the psychological support given to patients as part of multidisciplinary pulmonary rehabilitation is considered to be an important component of these programmes [130,131].

It is important to recognise that there are links between the physiology of breathlessness in COPD and what patients tell us makes them feel breathless. This is true in terms of activities that cause or increase the intensity of breathlessness and the descriptors that they use to describe the sensation. The model presented here should provide those involved in the care of COPD patients with a structure to consider the reasons why a previously stable patient might have become more breathless, in terms of ventilatory load, capacity and neural respiratory drive, and what the most appropriate strategies for reducing breathlessness might be.

In this regard, it is useful to consider the physiological impact that defined groups of daily activities have on breathlessness. For example, activities using mostly the lower limbs, e.g. walking and climbing the stairs, cause breathlessness in a patient with profound lower limb muscle abnormalities because the reduced aerobic capacity of the muscles increases ventilatory drive, which then increases the load-capacity imbalance as a secondary event. Breathlessness during these activities should therefore be reduced if the strength and endurance of the leg muscles can be improved, e.g. as part of a pulmonary rehabilitation training programme. Although it is important to optimise bronchodilatation and reduce hyperinflation to enable patients to achieve a sufficiently high intensity of exercise to accomplish this, it is unlikely that breathlessness will be completely abolished during these activities if lower limb muscle function is not also improved and maintained. In contrast, the upper limb muscles are largely unaffected by the skeletal muscle abnormalities associated with COPD, and so daily activities involving upper limb movement, e.g. brushing hair and lifting groceries onto shelves, drive breathlessness primarily by the impact that they have on ventilatory mechanics. Therefore, improvements in breathlessness during these activities could be achieved without increases in upper limb muscle strength specifically but, for example, by reducing hyperinflation, medically or surgically, and using energy conservation techniques [132].

The development of a physiological model for breathlessness during daily activities in COPD also has implications for the development of instruments to measure breathlessness in COPD. When measuring breathlessness, it is important to have an understanding of the definition of breathlessness, the mechanisms driving breathlessness and the predicted mode of efficacy of interventions, as well as the dimensions of breathlessness that the chosen instrument has been designed to capture [8]. None of the currently available instruments for breathlessness in advanced disease [133] were developed in the context of a theoretical physiological model of breathlessness. 
4. Impact

3. Perception

Intensity
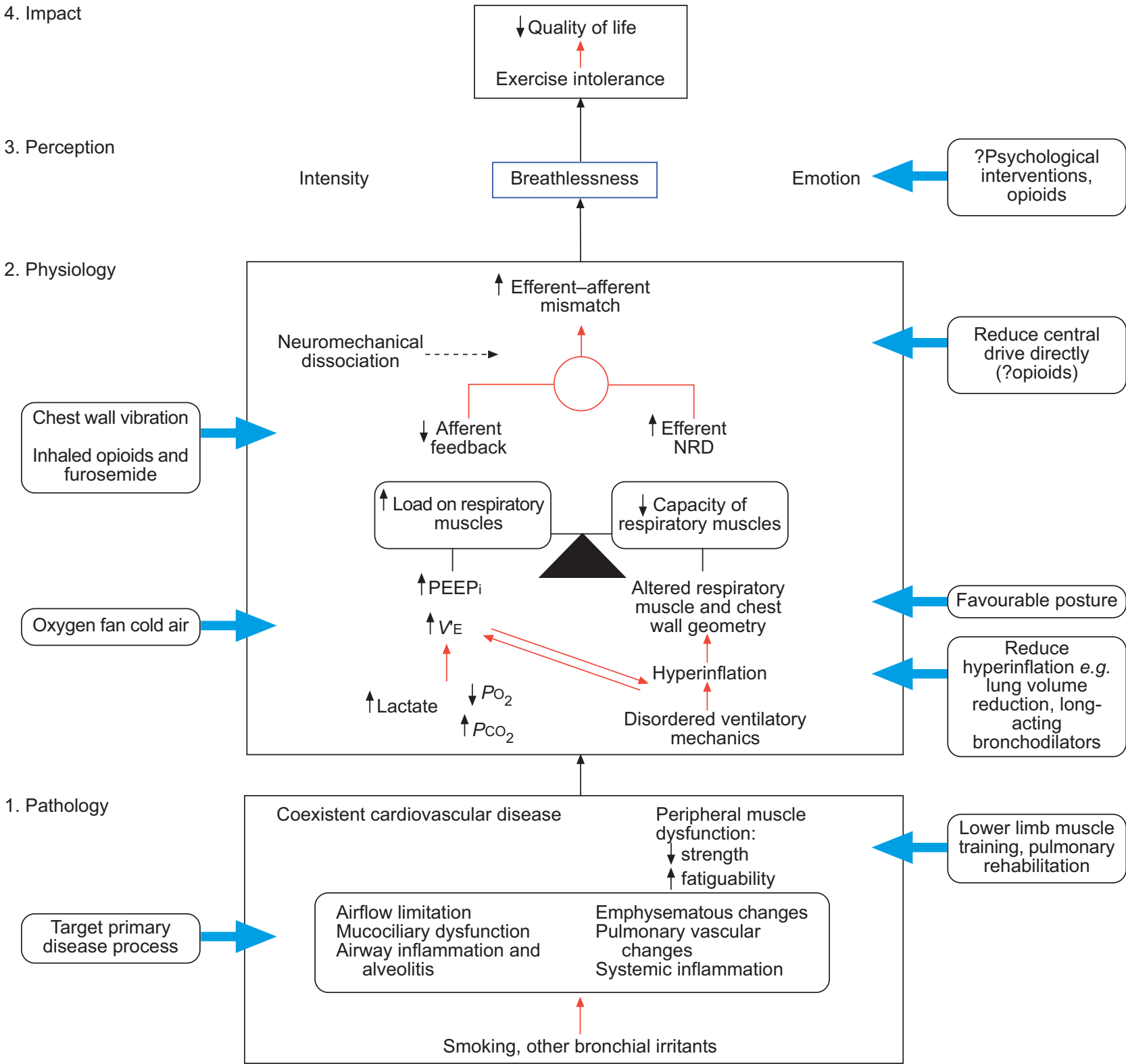

FIGURE 6. The physiological model can also be used to explain the mechanisms by which interventions impact on breathlessness. The final common physiological step is improved efferent-afferent mismatch through reductions in neuromechanical dissociation. Psychological support aims to impact on breathlessness distal to the physiological mechanisms. There is currently insufficient evidence to support the routine use of psychological interventions, such as counselling and support programmes and psychotherapy, alone to palliate breathlessness in routine clinical practice [129]. NRD: neural respiratory drive; PEEPi: intrinsic positive end-expiratory pressure; $V^{\prime} E$ : minute ventilation; $\mathrm{PO}_{2}$ : oxygen tension; $\mathrm{PCO}_{2}$ : carbon dioxide tension.

Instruments based on a robust physiological model of breathlessness may be better matched to the needs of studies seeking to demonstrate that an intervention improves breathlessness through a physiological mechanism. Indeed, the Food and Drug Administration has recommended that the development of a hypothesised conceptual framework is fundamental to the development of patient-reported outcome instruments [134]. Instruments focusing on the severity of breathlessness during daily activities, e.g. washing and dressing, which are an integral part of everyday life, are more likely to capture the magnitude of deteriorations and improvements in breathlessness than instruments focusing on nonessential activities that may be avoided if the patient associates them with intolerable breathlessness.

In summary, we have presented a model to describe the relationship between the physiological basis of breathlessness in COPD and patients' sensation of breathlessness during daily activities. This should help healthcare professionals to understand why COPD patients experience breathlessness during certain activities, and which interventions may be most beneficial when palliating breathlessness, and should facilitate the development of patient-reported outcome instruments to quantify breathlessness during activities of daily living in COPD. 


\section{REFERENCES}

1 Global Strategy for the Diagnosis, Management and Prevention of COPD. Global Initiative for Chronic Obstructive Lung Disease (GOLD), 2007. www.goldcopdcom/ Guidelineitem.asp?1152\&1251\&intId5989 Last accessed: March 30, 2009. Last updated: 2008.

2 Buist AS, McBurnie MA, Vollmer WM, et al. International variation in the prevalence of COPD (the BOLD Study): a population-based prevalence study. Lancet 2007; 370: 741-750.

3 World Health Organization. World Health Statistics, 2008. www.who.int/whosis/whostat/EN_WHS08_Full. pdf Geneva, World Health Organization.

4 British Thoracic Society. The burden of lung disease: a statistical report from the British Thoracic Society. 2nd Edn. London, British Thoracic Society, 2006.

5 Elkington $\mathrm{H}$, White $\mathrm{P}$, Addington-Hall J, et al. The last year of life of COPD: a qualitative study of symptoms and services. Respir Med 2004; 98: 439-445.

6 Pitta F, Troosters T, Spruit MA, et al. Characteristics of physical activities in daily life in chronic obstructive pulmonary disease. Am J Respir Crit Care Med 2005; 171: 972-977.

7 Garcia-Aymerich J, Felez MA, Escarrabill J, et al. Physical activity and its determinants in severe chronic obstructive pulmonary disease. Med Sci Sports Exerc 2004; 36: 1667-1673.

8 Meek PM. Measurement of dyspnea in chronic obstructive pulmonary disease: what is the tool telling you? Chron Respir Dis 2004; 1: 29-37.

9 O'Donnell DE, Banzett RB, Carrieri-Kohlman V, et al. Pathophysiology of dyspnea in chronic obstructive pulmonary disease: a roundtable. Proc Am Thorac Soc 2007; 4: 145-168.

10 O'Donnell DE. Hyperinflation, dyspnea, and exercise intolerance in chronic obstructive pulmonary disease. Proc Am Thorac Soc 2006; 3: 180-184.

11 Mahler DA. Mechanisms and measurement of dyspnea in chronic obstructive pulmonary disease. Proc Am Thorac Soc 2006; 3: 234-238.

12 Dyspnea. Mechanisms, assessment, and management: a consensus statement. American Thoracic Society. Am J Respir Crit Care Med 1999; 159: 321-340.

13 Howell JBL, Campbell EJM, eds. Breathlessness: proceedings of an international symposium held on 7 and 8 April 1965 under the auspices of the University of Manchester. Oxford, Blackwell Scientific Publications, 1966.

14 Killian KJ, Gandevia SC, Summers E, et al. Effect of increased lung volume on perception of breathlessness, effort, and tension. J Appl Physiol 1984; 57: 686-691.

15 Killian K, Campbell M. Dyspnea. In: Roussos C, ed. The Thorax. New York, Marcel Dekker, 1995; pp. 1709-1747.

16 Adams L, Lane R, Shea SA, et al. Breathlessness during different forms of ventilatory stimulation: a study of mechanisms in normal subjects and respiratory patients. Clin Sci (Lond) 1985; 69: 663-672.

17 Campbell EJ, Howell JB. The sensation of breathlessness. Br Med Bull 1963; 19: 36-40.

18 Manning HL, Shea SA, Schwartzstein RM, et al. Reduced tidal volume increases "air hunger" at fixed $\mathrm{PCO}_{2}$ in ventilated quadriplegics. Respir Physiol 1992; 90: 19-30.
19 Edo H, Kimura H, Niijima M, et al. Effects of chest wall vibration on breathlessness during hypercapnic ventilatory response. J Appl Physiol 1998; 84: 1487-1491.

20 Banzett RB, Lansing RW, Brown R, et al. "Air hunger' from increased $\mathrm{PCO}_{2}$ persists after complete neuromuscular block in humans. Respir Physiol 1990; 81: 1-17.

21 Taguchi O, Kikuchi Y, Hida W, et al. Effects of bronchoconstriction and external resistive loading on the sensation of dyspnea. J Appl Physiol 1991; 71: 2183-2190.

22 Raj H, Singh VK, Anand A, et al. Sensory origin of lobeline-induced sensations: a correlative study in man and cat. J Physiol 1995; 482: 235-246.

23 Chonan T, Mulholland MB, Leitner J, et al. Sensation of dyspnea during hypercapnia, exercise, and voluntary hyperventilation. J Appl Physiol 1990; 68: 2100-2106.

24 Sibuya M, Yamada M, Kanamaru A, et al. Effect of chest wall vibration on dyspnea in patients with chronic respiratory disease. Am J Respir Crit Care Med 1994; 149: 1235-1240.

25 Fujie $\mathrm{T}$, Tojo $\mathrm{N}$, Inase $\mathrm{N}$, et al. Effect of chest wall vibration on dyspnea during exercise in chronic obstructive pulmonary disease. Respir Physiol Neurobiol 2002; 130: 305-316.

26 Guz A. Brain, breathing and breathlessness. Respir Physiol 1997; 109: 197-204.

27 von Leupoldt A, Dahme B. Cortical substrates for the perception of dyspnea. Chest 2005; 128: 345-354.

28 Banzett RB, Mulnier HE, Murphy K, et al. Breathlessness in humans activates insular cortex. Neuroreport 2000; 11: 2117-2120.

29 Gracely RH, Undem BJ, Banzett RB. Cough, pain and dyspnoea: similarities and differences. Pulm Pharmacol Ther 2007; 20: 433-437.

30 Kim V, Rogers TJ, Criner GJ. New concepts in the pathobiology of chronic obstructive pulmonary disease. Proc Am Thorac Soc 2008; 5: 478-485.

31 Shapiro SD, Ingenito EP. The pathogenesis of chronic obstructive pulmonary disease: advances in the past 100 years. Am J Respir Cell Mol Biol 2005; 32: 367-372.

32 Rimington J. Smoking, chronic bronchitis, and lung cancer. Br Med J 1971; 2: 373-375.

33 Silverman EK, Speizer FE. Risk factors for the development of chronic obstructive pulmonary disease. Med Clin North Am 1996; 80: 501-522.

34 Falk GA, Briscoe WA. Alpha-1-antitrypsin deficiency in chronic obstructive pulmonary disease. Ann Intern Med 1970; 72: 427-429.

35 Hersh CP, DeMeo DL, Silverman EK. National Emphysema Treatment Trial state of the art: genetics of emphysema. Proc Am Thorac Soc 2008; 5: 486-493.

36 Molfino NA. Genetics of COPD. Chest 2004; 125: 1929-1940.

37 Barnes PJ, Rahman I. New concepts in chronic obstructive pulmonary disease oxidative stress, chromatin remodeling and gene transcription in inflammation and chronic lung diseases. Annu Rev Med 2003; 54: 113-129.

38 Rahman I. Oxidative stress, chromatin remodeling and gene transcription in inflammation and chronic lung diseases. J Biochem Mol Biol 2003; 36: 95-109.

39 Rogers DF, Cosio MG, Hale KA, et al. The airway goblet cell morphologic and morphometric effects of prolonged 
cigarette smoking on the small airways. Int J Biochem Cell Biol 2003; 35: 1-6.

40 Maestrelli P, Saetta M, Mapp CE, et al. Remodeling in response to infection and injury. Airway inflammation and hypersecretion of mucus in smoking subjects with chronic obstructive pulmonary disease. Am J Respir Crit Care Med 2001; 164: S76-S80.

41 Cosio MG, Hale KA, Niewoehner DE. Morphologic and morphometric effects of prolonged cigarette smoking on the small airways. Am Rev Respir Dis 1980; 122: 265-221.

42 Smaldone GC, Foster WM, O'Riordan TG, et al. Regional impairment of mucociliary clearance in chronic obstructive pulmonary disease. Chest 1993; 103: 1390-1396.

43 Shapiro SD. Proteinases in chronic obstructive pulmonary disease. Biochem Soc Trans 2002; 30: 98-102.

44 Nadel JA. Role of neutrophil elastase in hypersecretion during COPD exacerbations, and proposed therapies. Chest 2000; 117: Suppl. 2, 386S-389S.

45 Celli BR, Barnes PJ. Exacerbations of chronic obstructive pulmonary disease. Eur Respir J 2007; 29: 1224-1238.

46 Bathoorn E, Kerstjens H, Postma D, et al. Airways inflammation and treatment during acute exacerbations of COPD. Int J Chron Obstruct Pulmon Dis 2008; 3: 217-229.

47 Donaldson GC, Seemungal TA, Bhowmik A, et al. Relationship between exacerbation frequency and lung function decline in chronic obstructive pulmonary disease. Thorax 2002; 57: 847-852.

48 Wouters EF, Creutzberg EC, Schols AM. Systemic effects in COPD. Chest 2002; 121: Suppl. 5, 127S-130S.

49 Oudijk E-JD, Lammers JW, Koenderman L. Systemic inflammation in chronic obstructive pulmonary disease. Eur Respir J 22, 2003: Suppl. 46, 5s-13s.

50 Wouters EF. Local and systemic inflammation in chronic obstructive pulmonary disease. Proc Am Thorac Soc 2005; 2: 26-33.

51 Wasswa-Kintu S, Gan WQ, Man SFP, et al. Relationship between reduced forced expiratory volume in one second and the risk of lung cancer: a systematic review and meta-analysis. Thorax 2005; 60: 570-575.

52 Sin DD, Wu L, Man SFP. The relationship between reduced lung function and cardiovascular mortality: a population-based study and a systematic review of the literature. Chest 2005; 127: 1952-1959.

53 Schols AM, Buurman WA, Staal van den Brekel AJ, et al. Evidence for a relation between metabolic derangements and increased levels of inflammatory mediators in a subgroup of patients with chronic obstructive pulmonary disease. Thorax 1996; 51: 819-824.

54 DiFrancia M, Barbier D, Mege JL, et al. Tumor necrosis factor$\alpha$ levels and weight loss in chronic obstructive pulmonary disease. Am J Respir Crit Care Med 1994; 150: 1453-1455.

55 WagnerPD.Skeletal muscles in chronic obstructive pulmonary disease: deconditioning, or myopathy? Respirology 2006; 11: 681-686.

56 Killian KJ, Leblanc P, Martin DH, et al. Exercise capacity and ventilatory, circulatory, and symptom limitation in patients with chronic airflow limitation. Am Rev Respir Dis 1992; 146: 935-940.

57 Bernard S, Leblanc P, Whittom F, et al. Peripheral muscle weakness in patients with chronic obstructive pulmonary disease. Am J Respir Crit Care Med 1998; 158: 629-634.
58 Gosker HR, Engelen MP, van Mameren H, et al. Muscle fiber type IIX atrophy is involved in the loss of fat-free mass in chronic obstructive pulmonary disease. Am J Clin Nutr 2002; 76: 113-119.

59 Gosselink R, Troosters T, Decramer M. Peripheral muscle weakness contributes to exercise limitation in COPD. Am J Respir Crit Care Med 1996; 153: 976-980.

60 Hamilton AL, Killian KJ, Summers E, et al. Muscle strength, symptom intensity, and exercise capacity in patients with cardiorespiratory disorders. Am J Respir Crit Care Med 1995; 152: 2021-2031.

61 Serres I, Gautier V, Prefaut C, et al. Impaired skeletal muscle endurance related to physical inactivity and altered lung function in COPD patients. Chest 1998; 113: 900-905.

62 Coronell C, Orozco-Levi M, Mendez R, et al. Relevance of assessing quadriceps endurance in patients with COPD. Eur Respir J 2004; 24: 129-136.

63 Saey D, Debigare R, LeBlanc P, et al. Contractile leg fatigue after cycle exercise: a factor limiting exercise in patients with chronic obstructive pulmonary disease. Am J Respir Crit Care Med 2003; 168: 425-430.

64 Jakobsson P, Jorfeldt L, Brundin A. Skeletal muscle metabolites and fibre types in patients with advanced chronic obstructive pulmonary disease (COPD), with and without chronic respiratory failure. Eur Respir J 1990; 3: 192-196.

65 Maltais F, Simard AA, Simard C, et al. Oxidative capacity of the skeletal muscle and lactic acid kinetics during exercise in normal subjects and in patients with COPD. Am J Respir Crit Care Med 1996; 153: 288-293.

66 Maltais F, Jobin J, Sullivan MJ, et al. Metabolic and hemodynamic responses of lower limb during exercise in patients with COPD. J Appl Physiol 1998; 84: 1573-1580.

67 Weitzenblum E, Sautegeau A, Ehrhart M, et al. Long-term course of pulmonary arterial pressure in chronic obstructive pulmonary disease. Am Rev Respir Dis 1984; 130: 993-998.

68 Scharf SM, Iqbal M, Keller C, et al. Hemodynamic characterization of patients with severe emphysema. Am J Respir Crit Care Med 2002; 166: 314-322.

69 Kessler R, Faller M, Weitzenblum E, et al. "Natural history" of pulmonary hypertension in a series of 131 patients with chronic obstructive lung disease. Am J Respir Crit Care Med 2001; 164: 219-224.

70 Glaser S, Noga O, Koch B, et al. Impact of pulmonary hypertension on gas exchange and exercise capacity in patients with pulmonary fibrosis. Respir Med 2008; 103: 317-324

71 Hogg JC, Macklem PT, Thurlbeck WM. Site and nature of airway obstruction in chronic obstructive lung disease. $N$ Engl J Med 1968; 278: 1355-1360.

72 O'Donnell DE, Revill SM, Webb KA. Dynamic hyperinflation and exercise intolerance in chronic obstructive pulmonary disease. Am J Respir Crit Care Med 2001; 164: 770-777.

73 Haluszka J, Chartrand DA, Grassino AE, et al. Intrinsic PEEP and arterial PCO2 in stable patients with chronic obstructive pulmonary disease. Am Rev Respir Dis 1990; 141: 1194-1197.

74 O'Donnell DE, D'Arsigny C, Fitzpatrick M, et al. Exercise hypercapnia in advanced chronic obstructive pulmonary 
disease: the role of lung hyperinflation. Am J Respir Crit Care Med 2002; 166: 663-668.

75 Guerin C, Coussa ML, Eissa NT, et al. Lung and chest wall mechanics in mechanically ventilated COPD patients. J Appl Physiol 1993; 74: 1570-1580.

76 Wagner P, Danzker D, Dueck R. Ventilation-perfusion inequality in chronic obstructive pulmonary diseases. J Clin Invest 1977; 59: 203-216.

77 Byrd RB, Hyatt RE. Maximal respiratory pressures in chronic obstructive lung disease. Am Rev Respir Dis 1968; 98: 848-856.

78 Gordon AM, Huxley AF, Julian FJ. The variation in isometric tension with sarcomere length in vertebrate muscle fibres. J Physiol 1966; 184: 170-192.

79 Cassart M, Pettiaux N, Gevenois PA, et al. Effect of chronic hyperinflation on diaphragm length and surface area. Am J Respir Crit Care Med 1997; 156: 504-508.

80 Mead J. Functional significance of the area of apposition of diaphragm to rib cage [proceedings]. Am Rev Respir Dis 1979; 119: 31-32.

81 Polkey MI, Kyroussis D, Hamnegard CH, et al. Diaphragm strength in chronic obstructive pulmonary disease. Am J Respir Crit Care Med 1996; 154: 1310-3107.

82 O'Donnell DE, Webb KA. Exertional breathlessness in patients with chronic airflow limitation. The role of lung hyperinflation. Am Rev Respir Dis 1993; 148: 1351-1357.

83 Man WD, Mustfa N, Nikoletou D, et al. Effect of salmeterol on respiratory muscle activity during exercise in poorly reversible COPD. Thorax 2004; 59: 471-476.

84 Hopkinson NS, Toma TP, Hansell DM, et al. Effect of bronchoscopic lung volume reduction on dynamic hyperinflation and exercise in emphysema. Am J Respir Crit Care Med 2005; 171: 453-460.

85 Porszasz J, Emtner M, Goto S, et al. Exercise training decreases ventilatory requirements and exercise-induced hyperinflation at submaximal intensities in patients with COPD. Chest 2005; 128: 2025-2034.

86 Somfay A, Porszasz J, Lee SM, et al. Dose-response effect of oxygen on hyperinflation and exercise endurance in nonhypoxaemic COPD patients. Eur Respir J 2001; 18: 77-84.

87 Bellemare F, Grassino A. Force reserve of the diaphragm in patients with chronic obstructive pulmonary disease. $J$ Appl Physiol 1983; 55: 8-15.

88 De Troyer A, Leeper JB, McKenzie DK, et al. Neural drive to the diaphragm in patients with severe COPD. Am J Respir Crit Care Med 1997; 155: 1335-1340.

89 Gandevia SC, Leeper JB, McKenzie DK, et al. Discharge frequencies of parasternal intercostal and scalene motor units during breathing in normal and COPD subjects. Am J Respir Crit Care Med 1996; 153: 622-628.

90 Sinderby C, Beck J, Spahija J, et al. Voluntary activation of the human diaphragm in health and disease. J Appl Physiol 1998; 85: 2146-2158.

91 Jolley CJ, Luo YM, Steier J, et al. Neural respiratory drive in healthy subjects and in COPD. Eur Respir J 2009; 33: 289-297.

92 Spence DP, Graham DR, Ahmed J, et al. Does cold air affect exercise capacity and dyspnea in stable chronic obstructive pulmonary disease? Chest 1993; 103: 693-696.

93 Burgess KR, Whitelaw WA. Effects of nasal cold receptors on pattern of breathing. J Appl Physiol 1988; 64: $371-376$.
94 Wilson RH, Hoseth W, Dempsey ME. Respiratory acidosis. I. Effects of decreasing respiratory minute volume in patients with severe chronic pulmonary emphysema, with specific reference to oxygen, morphine and barbiturates. Am J Med 1954; 17: 464-470.

95 Weil JV, McCullough RE, Kline JS, et al. Diminished ventilatory response to hypoxia and hypercapnia after morphine in normal man. $N$ Engl J Med 1975; 292: 1103-1106.

96 Santiago TV, Johnson J, Riley DJ, et al. Effects of morphine on ventilatory response to exercise. J Appl Physiol 1979; 47: 112-118.

97 Clemens KE, Klaschik E. Symptomatic therapy of dyspnea with strong opioids and its effect on ventilation in palliative care patients. J Pain Symptom Manage 2007; 33: $473-481$.

98 Clemens KE, Klaschik E. Effect of hydromorphone on ventilation in palliative care patients with dyspnea. Support Care Cancer 2008; 16: 93-99.

99 Kallet RH. The role of inhaled opioids and furosemide for the treatment of dyspnea. Respir Care 2007; 52: 900-910.

100 Sinderby C, Spahija J, Beck J, et al. Diaphragm activation during exercise in chronic obstructive pulmonary disease. Am J Respir Crit Care Med 2001; 163: 1637-1641.

101 O'Donnell DE, Hamilton AL, Webb KA. Sensorymechanical relationships during high-intensity, constantwork-rate exercise in COPD. J Appl Physiol 2006; 101: 1025-1035.

102 Manning HL, Schwartzstein RM. Pathophysiology of dyspnea. N Engl J Med 1995; 333: 1547-1553.

103 Hodgev V, Kostianev S, Marinov B. University of Cincinnati Dyspnea Questionnaire for Evaluation of Dyspnoea during physical and speech activities in patients with chronic obstructive pulmonary disease: a validation analysis. Clin Physiol Funct Imaging 2003; 23: 269-274.

104 Garrod R, Bestall JC, Paul EA, et al. Development and validation of a standardized measure of activity of daily living in patients with severe COPD: the London Chest Activity of Daily Living scale (LCADL). Respir Med 2000; 94: 589-596.

105 Franssen FM, Wouters EF, Baarends EM, et al. Arm mechanical efficiency and arm exercise capacity are relatively preserved in chronic obstructive pulmonary disease. Med Sci Sports Exerc 2002; 34: 1570-1576.

106 Alison JA, Regnis JA, Donnelly PM, et al. End-expiratory lung volume during arm and leg exercise in normal subjects and patients with cystic fibrosis. Am J Respir Crit Care Med 1998; 158: 1450-1458.

107 Gigliotti F, Coli C, Bianchi R, et al. Arm exercise and hyperinflation in patients with COPD: effect of arm training. Chest 2005; 128: 1225-1232.

108 Couser JI Jr, Martinez FJ, Celli BR. Respiratory response and ventilatory muscle recruitment during arm elevation in normal subjects. Chest 1992; 101: 336-340.

109 Celli B, Criner G, Rassulo J. Ventilatory muscle recruitment during unsupported arm exercise in normal subjects. J Appl Physiol 1988; 64: 1936-1941.

110 Tangri S, Woolf CR. The breathing pattern in chronic obstructive lung disease during the performance of some common daily activities. Chest 1973; 63: 126-127. 
111 Celli BR, Rassulo J, Make BJ. Dyssynchronous breathing during arm but not leg exercise in patients with chronic airflow obstruction. $N$ Engl J Med 1986; 314: 1485-1490.

112 Velloso M, Stella SG, Cendon S, et al. Metabolic and ventilatory parameters of four activities of daily living accomplished with arms in COPD patients. Chest 2003; 123: 1047-1053.

113 Sharp JT, Drutz WS, Moisan T, et al. Postural relief of dyspnea in severe chronic obstructive pulmonary disease. Am Rev Respir Dis 1980; 122: 201-211.

114 Barach AL. Chronic obstructive lung disease: postural relief of dyspnea. Arch Phys Med Rehabil 1974; 55: 494-504.

115 O'Neill S, McCarthy DS. Postural relief of dyspnoea in severe chronic airflow limitation: relationship to respiratory muscle strength. Thorax 1983; 38: 595-600.

116 Eltayara L, Ghezzo H, Milic-Emili J. Orthopnea and tidal expiratory flow limitation in patients with stable COPD. Chest 2001; 119: 99-104.

117 Heijdra YF, Dekhuijzen PN, van Herwaarden CL, et al. Effects of body position, hyperinflation, and blood gas tensions on maximal respiratory pressures in patients with chronic obstructive pulmonary disease. Thorax 1994; 49: 453-458.

118 Druz WS, Sharp JT. Electrical and mechanical activity of the diaphragm accompanying body position in severe chronic obstructive pulmonary disease. Am Rev Respir Dis 1982; 125: 275-280.

119 Ambrosino N, Scano G. Dyspnoea and its measurement. Breathe 2004; 1: 101-107.

120 Elliott MW, Adams L, Cockcroft A, et al. The language of breathlessness. Use of verbal descriptors by patients with cardiopulmonary disease. Am Rev Respir Dis 1991; 144: 826-832.

121 Williams M, Cafarella $\mathrm{P}$, Olds $\mathrm{T}$, et al. The language of breathlessness differentiates between patients with coped and age-matched adults. Chest 2008; 134: 489-496.

122 Caroci Ade S, Lareau SC. Descriptors of dyspnea by patients with chronic obstructive pulmonary disease versus congestive heart failure. Heart Lung 2004; 33: 102-110.

123 Simon PM, Schwartzstein RM, Weiss JW, et al. Distinguishable types of dyspnea in patients with shortness of breath. Am Rev Respir Dis 1990; 142: 1009-1014.
124 Moy ML, Woodrow Weiss J, et al. Quality of dyspnea in bronchoconstriction differs from external resistive loads. Am J Respir Crit Care Med 2000; 162: 451-455.

125 Lansing RW, Im BSH, Thwing JI, et al. The perception of respiratory work and effort can be independent of the perception of air hunger. Am J Respir Crit Care Med 2000; 162: 1690-1696.

126 von Leupoldt A, Dahme B. Differentiation between the sensory and affective dimension of dyspnea during resistive load breathing in normal subjects. Chest 2005; 128: 3345-3349.

127 Carrieri-Kohlman V, Gormley JM, Eiser S, et al. Dyspnea and the affective response during exercise training in obstructive pulmonary disease. Nurs Res 2001; 50: 136-146.

128 von Leupoldt A, Sommer T, Kegat S, et al. The unpleasantness of perceived dyspnea is processed in the anterior insula and amygdala. Am J Respir Crit Care Med 2008; 177: 1026-1032.

129 Bausewein C, Booth S, Gysels M, et al. Non-pharmacological interventions for breathlessness in advanced stages of malignant and non-malignant diseases. Cochrane Database Syst Rev 2008; 2: CD005623.

130 Troosters T, Casaburi R, Gosselink R, et al. Pulmonary rehabilitation in chronic obstructive pulmonary disease. Am J Respir Crit Care Med 2005; 172: 19-38.

131 Nici L, Donner C, Wouters E, et al. American Thoracic Society/European Respiratory Society statement on pulmonary rehabilitation. Am J Respir Crit Care Med 2006; 173: 1390-1413.

132 Velloso M, Jardim JR. Study of energy expenditure during activities of daily living using and not using body position recommended by energy conservation techniques in patients with COPD. Chest 2006; 130: 126-132.

133 Bausewein C, Farquhar M, Booth S, et al. Measurement of breathlessness in advanced disease: a systematic review. Respir Med 2007; 101: 399-410.

134 U.S. Food and Drug Administration. Guidance for Industry. Patient-Reported Outcome Measures: Use in Medical Product Development to Support Labeling Claims. Draft Guidance. 2006. www.fda.gov/cder/ guidance/5460dft.htm Date last accessed: March 30, 2009. 